\title{
Tolerance against tumor necrosis factor $\alpha$ (TNF)-induced hepatotoxicity in mice: the role of nitric oxide
}

\author{
Ines Bohlinger, Marcel Leist, Johannes Barsig, Stefan Uhlig, Gisa Tiegs*, Albrecht \\ Wendel
}

Faculty of Biology, University of Konstanz, POB 5560-M668, D-78434 Konstanz, Germany

\begin{abstract}
D-Galactosamine-sensitized mice challenged with tumor necrosis factor $\alpha$ (TNF) developed severe apoptotic and secondary necrotic liver injury as assessed by histology, measurement of cytosolic DNA fragments and determination of liver-specific enzymes in plasma. Pretreatment of mice with interleukin- $\beta$ (IL-1) resulted in elevated levels of nitrite/nitrate in serum and rendered mice insensitive towards TNF toxicity. Pharmacological doses of the nitric oxide (NO) donor sodium nitroprusside (SNP) also conferred complete protection against TNF toxicity, suggesting a possible link between IL-1- and NO-induced protection. However, NO-synthesis inhibition by $\mathrm{N}^{\mathrm{G}}$-monomethyl-L-arginine failed to abrogate IL-1-induced tolerance against TNF toxicity. We conclude that IL-1 and NO protect against TNF-induced liver injury through distinct pathways.
\end{abstract}

Keywords: Interleukin-1; Sodium nitroprusside; Liver injury; Necrosis; Apoptosis; Galactosamine

\section{Introduction}

Tumor necrosis factor $\alpha$ (TNF) has been recognized as one of the key inflammatory mediators of bacterial lipopolysaccharides (LPS) and has been shown to mediate lethal shock and multi-organ failure. Transcriptional inhibitors such as the liver-specific agent D-galactosamine (GalN) or actinomycin D (ActD) sensitize mice several thousand-fold towards LPS or TNF [1]. In these models animals develop a relatively selective liver damage which allows quantitative assessment of TNF-toxicity by measurement of

\footnotetext{
* Corresponding author. Tel.: +497531 883 740; Fax: +49 7531883099.
}

liver-specific plasma enzymes [1]. Pretreatment of mice by either.LPS, or TNF, or interleukin- $1 \beta$ (IL-1) confers complete tolerance to an otherwise lethal second challenge with LPS or TNF. Tolerance was suggested to be due to one or several protective proteins synthesized within the liver [2].

Circumstantial evidence suggested the involvement of nitric oxide synthase (NOS) in the development of tolerance towards LPS- or cytokine-induced toxicity. NO was shown to be produced in considerable amounts by murine hepatocytes stimulated with cytokines [3]. Moreover, it was shown that endogenously produced NO reduced endotoxin-induced lethality as well as hepatic or renal organ damage [4-6]. Since 
IL-1 is both a strong inducer of NOS [7] as well as a potent agent for induction of tolerance [2], we investigated whether there might exist a causal relation between IL-1-mediated NO formation and tolerance to TNF-induced liver damage in GalN-sensitized mice.

\section{Materials and methods}

\subsection{Animal experiments}

Male BALB/c mice from the animal house of the University of Konstanz, Germany, received humane care in compliance with the legal requirements in Germany. All substances were administered in pyrogen-free saline. Sodium nitroprusside (SNP, $1.7 \mathrm{mg} / \mathrm{kg}$, Fluka, Buchs, Switzerland) and GalN (700 mg/kg, Roth, Karlsruhe, Germany) were injected i.p. in a volume of 200 $\mu \mathrm{l}$, rhuIL-1 $\beta(10 \mu \mathrm{g} / \mathrm{kg}$, a gift from Dr. K. Vosbeck, Ciba Geigy, Basel, Switzerland), $\operatorname{rmuTNF} \alpha(10 \mu \mathrm{g} / \mathrm{kg}$, a gift from Dr. Adolf, Bender \& Co, Vienna, Austria) and $\mathrm{N}^{\mathrm{G}}$ monomethyl-L-arginine (NMMA, $175 \mathrm{mg} / \mathrm{kg}$, Sigma Chemical Co., St. Louis, MO) were injected i.v. in a volume of $300 \mu \mathrm{l}$. Animals were sacrificed by cervical dislocation 5 or $8 \mathrm{~h}$ after challenge and blood was withdrawn by cardiac puncture into heparinized syringes.

\subsection{Histology and DNA fragmentation}

Livers were perfused for $10 \mathrm{~s}$ as described [8] before they were excised. One slice of the large anterior lobe was immediately immersed in $4 \%$ formalin and imbedded in paraplast. Sections (2-3 $\mu \mathrm{m})$ were stained with hematoxylin/eosin. The remaining parts of the liver were homogenized. The homogenate was centrifuged at $13000 \times \mathrm{g}$ for $20 \mathrm{~min}$. The supernatant (final dilution 1250-fold) was used to measure DNA fragmentation with an ELISA kit (Boehringer, Mannheim, Germany) as described [8].

\subsection{Cell culture and incubation conditions}

Hepatocytes and non-parenchymal liver cells were isolated from 12-week-old male BALB/c mice by a two-step collagenase perfusion method and cultured as described [8].

\subsection{Enzyme assays}

Activities of alanine-aminotransferase (ALT) in plasma were determined according to [9].

\subsection{Nitrite determination in cell culture supernatants}

For determination of nitrite release, cells were incubated for $20 \mathrm{~h}$ in RPMI 1640 medium without phenol red. Culture supernatants were assayed for nitrite according to the Griess reaction.

\subsection{Nitrite determination in serum}

Nitrite in serum was measured essentially according to the method of Misko et al. [10], using the Griess assay.

\subsection{Statistics}

Data from in vivo experiments are given as means \pm S.E.M., all other data as means \pm S.D. Data for transaminases and DNA fragmentation were analysed by non-parametric analysis of variance (Kruskal-Wallis). Statistical analysis of serum nitrite/nitrate concentrations (Table 1) was done using the parametric Waller-DuncanTest. $P<0.05$ was considered to be significant.

\section{Results}

\subsection{IL-1-induced tolerance against GalN/TNF- mediated liver damage}

Intravenous administration of $10 \mu \mathrm{g} / \mathrm{kg}$ rmuTNF $\alpha$ to GalN-sensitized mice induced severe necrotic liver damage as determined by elevated plasma levels of ALT $8 \mathrm{~h}$ after challenge (6260 $\pm 1010 \mathrm{U} / 1$ vs. untreated control: $40 \pm 20 \mathrm{U} / 1, n=6, P<0.05)$. Liver necrosis was preceded by apoptotic changes. DNA fragmentation was increased $2.9 \pm 0.7$-fold $5 \mathrm{~h}$ after GalN/ TNF administration compared to GalN controls. Eight $\mathrm{h}$ after challenge DNA fragmentation was increased $3.6 \pm 0.4 *$-fold compared to controls (data \pm S.E.M., $n=3, * P<0.05$ ). Histological examination confirmed these findings: 3.5 or $5 \mathrm{~h}$ after injection of TNF to GalN-sensitized mice, hyperchromatic nuclear membranes and formation of apoptotic bodies were seen. Eight $h$ after GalN/TNF, numerous apoptotic bodies were identified between necrotic hepatocytes [11]. 
Table 1

Effect of the NOS inhibitor NMMA on IL-1-induced tolerance against liver injury caused by TNF $\alpha$ in galactosamine-sensitized mice

\begin{tabular}{llcll}
\hline Pretreatment $^{\mathrm{a}}$ & Treatment $^{\mathrm{b}}$ & ALT $^{\mathrm{c}}(\mathrm{U} / \mathrm{l})$ & Nitrite/nitrate $^{\mathrm{c}}(\mu \mathrm{M})$ & $n$ \\
\hline Saline & GalN/TNF & $10130 \pm 2400$ & $35 \pm 11$ & 5 \\
IL-1 & GalN/TNF & $22 \pm 24^{*}$ & $32 \pm 6$ & 5 \\
IL-1 + NMMA & GalN/TNF + NMMA & $35 \pm 23^{*}$ & $34 \pm 10$ & 5 \\
NMMA & GalN/TNF + NMMA & $10380 \pm 3370$ & $27 \pm 8$ & 5 \\
IL-1 & Saline & $17 \pm 11^{*}$ & $77 \pm 14^{* *}$ & 5 \\
Saline & GalN & $90 \pm 9^{*}$ & $36 \pm 9$ & 3 \\
\hline
\end{tabular}

"Animals were pretreated $4 \mathrm{~h}$ before challenge by an i.v. dose of $10 \mu \mathrm{g} / \mathrm{kg}$ IL-1 \pm NMMA (175 mg/kg) or by injection of saline.

${ }^{\mathrm{b}}$ GalN (700 mg/kg) was administered i.p. simultaneously with TNF (10 $\mu \mathrm{g} / \mathrm{kg}$, i.v.) and NMMA (175 mg/kg, i.v.).

${ }^{\mathrm{c}}$ Plasma ALT was measured in $\mathrm{U} / 18 \mathrm{~h}$ after challenge, levels of nitrite/nitrate in plasma were determined $6 \mathrm{~h}$ after pretreatment. Data are means \pm S.E.M.

$* P<0.05$ vs. GalN/TNF control.

$* * P<0.05$ vs. all other groups.

$n$, number of animals per group.

Pretreatment of the animals with $10 \mu \mathrm{g} / \mathrm{kg}$ rhulL-1 $\beta$ i.v. $4 \mathrm{~h}$ before challenge led to a completely refractory state against TNF-induced cytotoxicity in GalN-sensitized mice, i.e. neither ALT release into plasma nor DNA fragmentation were significantly increased.

\subsection{Prevention of IL-1-induced tolerance by inhibition of hepatic transcription}

In order to study the role of hepatic biosynthesis in the development of tolerance, the liver-specific transcriptional inhibitor GalN was given together with IL-1 $4 \mathrm{~h}$ prior to GalN/TNFchallenge. Under this experimental condition we observed severe liver failure $8 \mathbf{h}$ after challenge (ALT: $8440 \pm 1940 \mathrm{U} / 1$ ). Mice treated with IL-1/ GalN and challenged $4 \mathrm{~h}$ later with GalN alone developed no liver injury. These observations imply active biosynthetic hepatic processes as a requirement for IL-1-induced tolerance.

\subsection{Protection against GalN/TNF-induced liver damage by administration of SNP}

Liver NOS is one of the putatively protective proteins [4-6] known to be induced by IL-1 [7]. In order to study a possible participation of $\mathrm{NO}$ in the development of tolerance, we first tested the efficacy of the pharmacological NO donor SNP against liver damage induced by TNF in
GalN-sensitized mice. Pretreatment with SNP (1.7 $\mathrm{mg} / \mathrm{kg}$ i.p., $15 \mathrm{~min}$ before challenge) protected against liver damage induced by GalN/ TNF as shown by significantly reduced levels of plasma ALT compared to GalN/TNF controls $(110 \pm 25 \mathrm{U} / 1$ vs. $8470 \pm 4120 \mathrm{U} / 1, n=5, P<$ $0.05)$. These results indicate that endogenous NO production from exogenous precursors has the potential to protect against TNF-mediated toxicity.

\subsection{IL-1-induced endogenous NO production}

Since pharmacologically delivered NO provided protection against TNF toxicity in vivo, we checked whether NO was produced endogenously upon treatment of mice with IL-1. Serum nitrite/nitrate levels were elevated $6 \mathbf{h}$ after administration of IL-1 as compared to salinetreated animals (Table 1). In order to identify the source of IL-1-induced endogenous NO production, hepatocyte and non-parenchymal liver cell cultures from IL-1 or saline-treated animals were prepared $4 \mathrm{~h}$ after pretreatment. Endogenous NO production was determined by measuring the amount of nitrite released into the culture supernatant. Hepatocytes were left untreated or were further stimulated by incubation with IL-1 (50 $\mathrm{ng} / \mathrm{ml}$ ). In vivo pretreatment with IL-1 lead to an increased ex vivo nitrite production in liver 
Table 2

Ex vivo nitrite production by hepatocytes of IL-1-pretreated and control mice

\begin{tabular}{llc}
\hline Pretreatment & (in vivo) & \multicolumn{2}{l}{ Stimulus (in vitro) } \\
\cline { 2 - 3 } & None & IL-1 $(50 \mathrm{ng} / \mathrm{ml})$ \\
\hline Saline & $<1^{\mathrm{b}}$ & $2.8 \pm 0.6$ \\
IL-1 & $4.8 \pm 1.2$ & $19.8 \pm 2.9$ \\
\hline
\end{tabular}

animals were pretreated $4 \mathrm{~h}$ before preparation of hepatocytes. IL-1 was given i.v. in a dose of $10 \mu \mathrm{g} / \mathrm{kg}$.

${ }^{b}$ Hepatocytes $\left(8 \times 10^{4}\right.$ per well) were incubated in RPMI 1640 for $20 \mathrm{~h}$ before the amount of nitrite was assayed in the supernatant. Data are means (nmol nitrite $/ 10^{6}$ cells) \pm S.D. of triplicate incubations.

cell cultures as compared to hepatocytes from saline-treated control animals (Table 2). This augmented basal release was further enhanced more than 4-fold when these already activated cells were incubated with IL-1 in vitro (Table 2). Additional experiments with the same mice showed that non-parenchymal liver cell cultures prepared from cells by differential centrifugation and plastic adhesion produced less than $5 \%$ per cell of the nitrite found in hepatocyte cultures, suggesting that the nitrite determined in the above experiments was predominantly derived from hepatocytes (data not shown).

\subsection{No impairment of tolerance by inhibition of NOS in vivo}

In order to study the relevance of endogenously formed NO for development of tolerance in vivo, endogenous NO production was inhibited by administration of NMMA $(2 \times 175 \mathrm{mg} / \mathrm{kg})$, a competitive inhibitor of NOS, together with IL-1 pretreatment and together with a subsequent TNF challenge. Administration of NMMA caused neither an altered toxicity of TNF in vivo nor any modification of the IL-1-induced tolerance in GalN-sensitized mice (Table 1).

\section{Discussion}

A large variety of experimental models have been used in order to study possible mechanisms of septic shock and ensuing organ failure. LPS as the primary initiator of a cytokine response or TNF as a distal mediator of. LPS toxicity are commonly used to elicit the systemic inflammatory response. However, pretreatment of mice with minute amounts of either one of these agents protects them from a second, otherwise lethal challenge. In the present study we used IL-1 to induce tolerance against TNF challenge in the low-dose model of the GalN-sensitized mouse.

A salient feature of the GalN/TNF model is apoptotic and secondary necrotic liver cell death [11]. We therefore measured cytosolic DNA fragments and hepatocyte-specific enzymes to quantitate organ injury. According to these parameters, IL-1 completely protected mice against hepatic injury induced by TNF. Since the development of tolerance could be completely abolished by co-administration of GalN, which selectively impairs the hepatic RNA synthesis [11] we conclude that IL-1-induced tolerance is an active process requiring hepatic transcription.

One putatively protective protein known to be induced by IL-1 is NOS, an enzyme producing the potent vasodilatator NO. Our finding that NOS activity is increased by incubation of murine liver cell cultures with IL-1 in vitro is in agreement with previous findings showing an induction of NOS mRNA in human hepatocytes under similar conditions [7]. In analogy to the in vitro experiments, treatment of mice with IL- 1 in vivo led to elevated levels of nitrite/nitrate in serum and to an increased NOS activity in liver cells ex vivo.

The role of endogenously produced $\mathrm{NO}$ in septic shock and other inflammatory models is not yet clarified. In order to study the significance of $\mathrm{NO}$ in TNF-induced liver failure in GalN-sensitized mice and to further investigate the role of endogenously formed NO for the development of tolerance, we examined in vivo whether injection of an NO-releasing agent (SNP) could substitute for IL-1 in the protection against TNF toxicity and which effects inhibition of NOS might have on IL-1-induced tolerance. The protection by SNP against TNF-induced hepatotoxicity is consistent with findings in the GalN/LPS model where various vasodilatators prevented liver injury [1]. Though an increased production of NO is probably responsible for the 
detrimental fall in blood pressure seen in septic shock [12], beneficial effects of this mediator in septic complications have also been described. For instance, an aggravation of LPS-induced hepatic damage in $C$. parvum-sensitized mice by administration of NMMA, a competitive inhibitor of NOS, was reported [5]. However, we found that NMMA administration at a dose described to block the endogenous NO formation [5] did not abolish IL-1-induced tolerance. This argues against a predominant role of endogenously produced $\mathrm{NO}$ in this inflammatory model and against a role of NO in the development of tolerance.

We conclude that IL-1 induces expression and/ or release of tolerogenic proteins different from NOS and that increased production of endogenous NO is not the mechanism responsible for tolerance development.

\section{References}

[1] Tiegs, G. (1994) Immunotoxicology of host-responsemediated experimental liver injury. J. Hepatol. 21, $890-903$.

[2] Libert, C., van Bladel, S., Brouckaert, P., Shaw, A. and Fiers, W. (1991) Involvement of the liver, but not of IL-6, in IL-1-induced desensitization to the lethal effects of tumor necrosis factor. J. Immunol. 46, 2625-2632.

[3] Adamson, G.M. and Billings, R.E. (1993) Cytokine toxicity and induction of NO synthase activity in cultured mouse hepatocytes. Toxicol. Appl. Pharmacol. 119, 100-107.

[4] Cobb, J.P., Natanson, C., Hoffman, W.D., Lodato, R.F., Banks, S., Koev, C.A., Solomon, M.A. et al. (1992) $\mathrm{N}^{\omega}$-amino-L-arginine, an inhibitor of nitric oxide synth- ase, raises vascular resistance but increases mortality rates in awake canines challenged with endotoxin. J. Exp. Med. 176, 1175-1182.

[5] Harbrecht, B.G., Billiar, T.R., Stadler, J., Demetris, A.J., Ochoa, J.B., Curran, R.D. and Simmons, R.L. (1992) Inhibition of nitric oxide synthesis during endotoxemia promotes intrahepatic thrombosis and an oxygen radical-mediated hepatic injury. J. Leukocyte Biol. 52, 390-394.

[6] Shultz, P.J. and Raij, L. (1992) Endogenously synthesized nitric oxide prevents endotoxin-induced glomerular thrombosis. J. Clin. Invest. 90, 1718-1725.

[7] Geller, D.A., Lowenstein, C.J., Shapiro, R.A., Nussler, A.K., Di Silvio, M., Wang, S.C., Nakayama, D.K., Simmons, R.L., Snyder, S.H. and Billiar, T.R. (1993) Molecular cloning and expression of inducible nitric oxide synthase from human hepatocytes. Proc. Natl. Acad. Sci. USA 90, 3491-3495.

[8] Leist, M., Gantner, F., Bohlinger, I., Germanin, P.G., Tiegs, G. and Wendel, A. (1994) Murine hepatocyte apoptosis induced in vitro and in vivo by TNF- $\alpha$ requires transcriptional arrest. J. Immunol. 153, 17781788.

[9] Bergmeyer, H.U. (1984) Methods of Enzymatic Analysis. Verlag Chemie, Weinheim.

[10] Misko, T.P., Schilling, R.J., Salvemini, D., Moore, W.M. and Currie, M.G. (1993) A fluorimetric assay for the measurement of nitrite in biological samples. Anal. Biochem. 214, 11-16.

[11] Leist, M., Gantner, F., Bohlinger, I., Tiegs, G., Germann, P.G. and Wendel, A. (1995) Characterization of TNF-induced murine hepatic apoptosis as a pathomechanism of septic liver failure. Am. J. Pathol. 146, 1220 1234.

[12] Petros, A., Lamb, G., Leone, A., Moncada, S., Bennett, D. and Vallance, P. (1994) Effects of a nitric oxide synthase inhibitor in humans with septic shock. Cardiovasc. Res. $28,34-39$. 